\title{
Bryosphere Loss Impairs Litter Decomposition Consistently Across Moss Species, Litter Types, and Micro-Arthropod Abundance
}

\author{
Roger Grau-Andrés, ${ }^{1 *} \odot$ David A. Wardle, ${ }^{2} \odot$ and Paul Kardol $^{1} \odot$
}

${ }^{1}$ Department of Forest Ecology and Management, Swedish University of Agricultural Sciences (SLU), Umeå, Sweden; ${ }^{2}$ Asian School of the Environment, Nanyang Technological University, Singapore, Singapore

\begin{abstract}
The bryosphere (that is, ground mosses and their associated biota) is a key driver of nutrient and carbon dynamics in many terrestrial ecosystems, in part because it regulates litter decomposition. However, we have a poor understanding of how litter decomposition responds to changes in the bryosphere, including changes in bryosphere cover, moss species, and bryosphere-associated biota. Specifically, the contribution of micro-arthropods to litter decomposition in the bryosphere is unclear. Here, we used a 16-month litterbag field experiment in two boreal forests to investigate bryosphere effects on litter decomposition rates among two moss species (Pleurozium schreberi and Hylocomium splendens), and two litter types (higherquality Betula pendula litter and lower-quality $P$. schreberi litter). Additionally, we counted all microarthropods in the litterbags and identified them to functional groups. We found that bryosphere removal reduced litter decomposition rates by $28 \%$ and micro-arthropod abundance by $29 \%$ and led to a colder micro-climate. Litter decomposition rates
\end{abstract}

Received 22 June 2021; accepted 5 December 2021

published online 20 December 2021

Supplementary information: The online version contains supplementary material available at https://doi.org/10.1007/s10021-021-0073 1-8.

Author contributions RGA and PK designed the experiment with input from DAW. RGA performed the research and analysed the data. RGA wrote the manuscript with input from PK and DAW.

*Corresponding author; e-mail: roger.grau.andres@slu.se and micro-arthropod abundance were uncorrelated overall, but were positively correlated in B. pendula litterbags. Bryosphere effects on litter decomposition rates were consistent across moss species, litter types, and micro-arthropod abundances and community compositions. These findings suggest that micro-arthropods play a minor role in litter decomposition in the boreal forest floor, suggesting that other factors (for example, micro-climate, nutrient availability) likely drive the positive effect of the bryosphere on decomposition rates. Our results point to a substantial and consistent impairment of litter decomposition in response to loss of moss cover, which could have important implications for nutrient and carbon cycling in mossdominated ecosystems.

Key words: collembola; mites; moss; litter mass loss; litterbag; litter quality; meso-fauna; boreal forest; Pleurozium schreberi; Hylocomium splendens.

\section{HighLIGHTS}

- Moss removal impaired litter decomposition and micro-arthropod abundance

- Moss effects on decomposition were unrelated to 
micro-arthropod abundance

- Moss species and litter quality did not alter moss removal effects on decomposition

\section{INTRODUCTION}

Mosses are particularly abundant in high latitude regions, where they often dominate the ground layer of peatlands, boreal forests, and tundra (Nilsson and Wardle 2005; Turetsky and others 2010; Street and others 2013). The bryosphere, that is, the ground bryophyte layer including senesced moss and its associated food web (Lindo and Gonzalez 2010), plays a key role in controlling carbon inputs to ecosystems due to its high net primary productivity, production of recalcitrant litter, and nutrient supply from moss-associated $\mathrm{N}$-fixing cyanobacteria (Turetsky and others 2010; Lindo and others 2013; Street and others 2013). Moreover, the bryosphere can also control rates of ecosystem carbon loss through effects on microclimate (Gornall and others 2007), which in turn affect biological activity and thus litter decomposition (De Long and others 2016). Given that moss cover in high-latitude ecosystems is susceptible to changes in climate (Elmendorf and others 2012; Alatalo and others 2020) and land-use (Vitt and others 2019), understanding how litter decomposition may respond to changes in the bryosphere is needed to more accurately predict the effect of environmental change on carbon cycling.

In boreal forests, the bryosphere often promotes litter decomposition relative to bare ground (Jackson and others 2011, 2013; De Long and others 2016). The proposed mechanism is that the bryosphere improves environmental conditions for the decomposer community through regulating temperature and moisture and increasing nutrient supply (Jackson and others 2011). Importantly, the bryosphere can host high abundances of microarthropods, especially mites and springtails (Lindo and Gonzalez 2010; Glime 2017), and loss of bryosphere cover has been observed to decrease micro-arthropod abundance in the ground of alpine heaths (Mitchell and others 2016) and boreal forests (Salmane and Brumelis 2008; Bokhorst and others 2014). Micro-arthropods can enhance litter decomposition directly by feeding on detritus (Maraun and others 2011; Magilton and others 2019) and indirectly by stimulating microbes (which are the primary agents of decomposition) through litter fragmentation and faecal production (Briones 2014; Coleman and others 2017). While some studies have reported neutral effects (Wall and others 2008; Barreto and Lindo 2018; Zhou and others 2020), numerous studies have shown that micro-arthropods can have important positive effects on litter decomposition (Schädler and Brandl 2005; Wall and others 2008; Wang and others 2009; Makkonen and others 2012; GarcíaPalacios and others 2013; Fujii and others 2018). Therefore, increased micro-arthropod abundance can potentially contribute to the positive effects of the bryosphere on litter decomposition. However, little is known about the importance of microarthropod abundance to litter decomposition in boreal forests (Makkonen and others 2012; GarcíaPalacios and others 2013). Moreover, whether and how the micro-arthropods impact on litter decomposition in the presence versus absence of a bryosphere remains unexplored.

The two feather moss species Pleurozium schreberi and Hylocomium splendens often dominate the forest floor in well-drained boreal forests (Nilsson and Wardle 2005). Physiological and morphological differences among moss species determine microhabitat structure and climate in the bryosphere, and this could influence the activity of the decomposer community. For example, patches dominated by $P$. schreberi are denser and better able to hold moisture than are patches dominated by $H$. splendens (Elumeeva and others 2011), thus potentially making them capable of supporting a greater abundance of micro-arthropods. Further, litter quality may mediate how micro-arthropods affect decomposition rates (García-Palacios and others 2013), and micro-arthropods may have a greater influence on decomposition of lowercompared to higher-quality litter in the bryosphere environment because lability of low-quality litter is further enhanced by soil fauna through the physical and chemical changes that they cause via litter fragmentation and partial digestion (Yang and Chen 2009; Milcu and Manning 2011; Joly and others 2020). Therefore, consideration of moss species identity and litter quality is needed to understand micro-arthropod effects on decomposition across a wider range of habitats, such as those varying in their types of bryospheres and litter inputs.

Here, we used a litterbag field experiment to investigate the effect of the bryosphere and of micro-arthropods on litter decomposition in the boreal forest floor. For this, we placed litterbags containing each of two types of litter (that is, higher-quality birch [Betula pendula] or lowerquality moss [P. schreberi] litter) in bryosphere plots dominated by either $P$. schreberi or $H$. splendens, and in adjacent plots where the bryosphere had been 
removed. We then measured micro-arthropod abundance in the litterbags and litter mass loss after 4 and 16 months. We hypothesised that: (1) Compared to bare ground, litter in the bryosphere has greater abundance of micro-arthropods and decomposes faster. This is because of improved micro-climatic conditions (Bokhorst and others 2014; De Long and others 2016); (2) bryosphere effects are greater in $P$. schreberi than in $H$. splendens bryospheres. This is because $P$. schreberi has a higher water holding capacity (Elumeeva and others 2011), and thus, decomposition is less moisturelimited; and 3) bryosphere effects are greater for lower-quality (moss) litter than for higher-quality (birch) litter, because lability of low-quality litter is further enhanced by micro-arthropods (Yang and Chen 2009), which are more abundant in bryosphere-covered plots. By examining the effect of bryosphere removal on micro-arthropod abundance and decomposition of two litters of contrasting quality, and across two widespread feather moss species, we aimed to better understand how the bryosphere controls litter decomposition in boreal forests.

\section{Methods}

\section{Study Site}

The study was carried out in Svartberget experimental forest, a mixed coniferous forest in northern Sweden $\left(64^{\circ} 15^{\prime} \mathrm{N}, 19^{\circ} 46^{\prime} \mathrm{E}, 270 \mathrm{~m}\right.$ a.s.l.; Figure la). The mean annual air temperature is $1.8^{\circ} \mathrm{C}$ (mean temperature in January is $-10.3{ }^{\circ} \mathrm{C}$ and, in July, $15.3{ }^{\circ} \mathrm{C}$ ), the mean annual precipitation is $620 \mathrm{~mm}$, and the ground is covered by snow for about 170 days/year (data period 19912019; Svartberget Research Station 2020). We used two nearby sites located about $1 \mathrm{~km}$ apart. The southernmost site $\left(64^{\circ} 14^{\prime} 43.83^{\prime \prime} \mathrm{N}, 19^{\circ} 45^{\prime} 42.95^{\prime \prime}\right.$ E) is a 110-year-old forest dominated by Picea abies $(80 \%)$ with some Pinus sylvestris $(20 \%)$, and the northernmost site $\left(64^{\circ} 15^{\prime} 12.84^{\prime \prime} \mathrm{N}, 19^{\circ} 45^{\prime} 56.37^{\prime \prime}\right.$ E) is a 120-year-old forest composed almost exclusively of Pinus sylvestris (Figure 1b). Betula spp. is present at both sites. The understory vascular plant vegetation is similar at both sites and is overall dominated by Vaccinium myrtillus (11\% cover), Vaccinium vitis-idaea (4\%) and graminoids $(1 \%)$. Continuous, mono-specific layers of the feather mosses Pleurozium schreberi and Hylocomium splendens are ubiquitous at both sites. The feather moss Ptilium crista-castrensis and the acrocarpous moss Dicranum sp. are also common but rarely dominate. $P$. schreberi and $H$. splendens bryospheres had similar thickness (that is, $7.2 \pm 0.4 \mathrm{~cm}$ [mean $\pm \mathrm{SE}$ ] and $7.7 \pm 0.4 \mathrm{~cm}$, respectively), but $P$. schreberi bryospheres were denser (that is, $16.9 \pm 1.6 \mathrm{mg} \mathrm{cm}^{-3}$ versus $11.3 \pm 0.6 \mathrm{mg} \mathrm{cm}^{-3}$, dry weight basis).

\section{Experimental Design and Litterbag Deployment}

We used the litterbag method to estimate decomposition rates from litter mass loss. To test the effect of different litter qualities on decomposition, we used two litter types of contrasting lability: senesced Betula pendula leaves (higher-quality litter; $\mathrm{C}: \mathrm{N}$ ratio $=49.0 \pm 0.9$ [mean $\pm \mathrm{SE}$ ], $\mathrm{N}=6$ independent sets of leaves), and senesced $P$. schreberi shoots (lower-quality litter; $\mathrm{C}: \mathrm{N}$ ratio $=70.2 \pm 1.4$, $\mathrm{N}=6$ independent sets of shoots). The choice of litter types was based on previous research showing that litter quality (including $\mathrm{N}$ content) and mass loss values differed greatly between $B$. pendula and P. schreberi (Wardle and others 2003). Both litter types were collected on 12 May 2019 (that is, shortly after snowmelt) from the forest floor in Umeå $\left(63^{\circ} 50^{\prime} \mathrm{N}, 20^{\circ} 20^{\prime} \mathrm{E}\right)$, about $50 \mathrm{~km}$ southeast of the study site. We selected freshly senesced $B$. pendula leaves (that is, those produced in the most recent autumn) on the forest floor. For $P$. schreberi litter, we harvested an intermediate 3$4 \mathrm{~cm}$ brown section of the shoot which was clearly separate from the upper green part and the lower, highly decomposed part, in line with Wardle and others (2003). Each of the two litter types was separately dried at $60{ }^{\circ} \mathrm{C}$ in a fan-assisted oven and homogenised. Nylon mesh litterbags $(10 \times 5 \mathrm{~cm})$ were then filled with $1.7 \mathrm{~g}$ (measured to three decimal places) of oven-dry litter (either B. pendula or P. schreberi litter). Some litter fragmentation occurred during the process of filling the litterbags with whole leaves or shoots. To achieve a wider range of micro-arthropod abundances among the litterbags, we used litterbags of two different mesh sizes: $1.3 \times 1.1 \mathrm{~mm}$, and $1.0 \times 0.2 \mathrm{~mm}$ (Bokhorst and Wardle 2013). Although both mesh sizes allow micro-arthropod access, the greater physical impediment in the small size litterbags could potentially influence the micro-arthropod community through slowing colonisation or excluding large individuals. In total, we prepared 320 litterbags (that is, 80 for each combination of two mesh sizes and two litter types).

On 25 May 2019, eight litterbags were deployed in each of 40 randomly chosen plots $(20$ in each site) where the bryosphere was dominated (that is, cover $>90 \%$ ) by either $P$. schreberi (10 plots in 


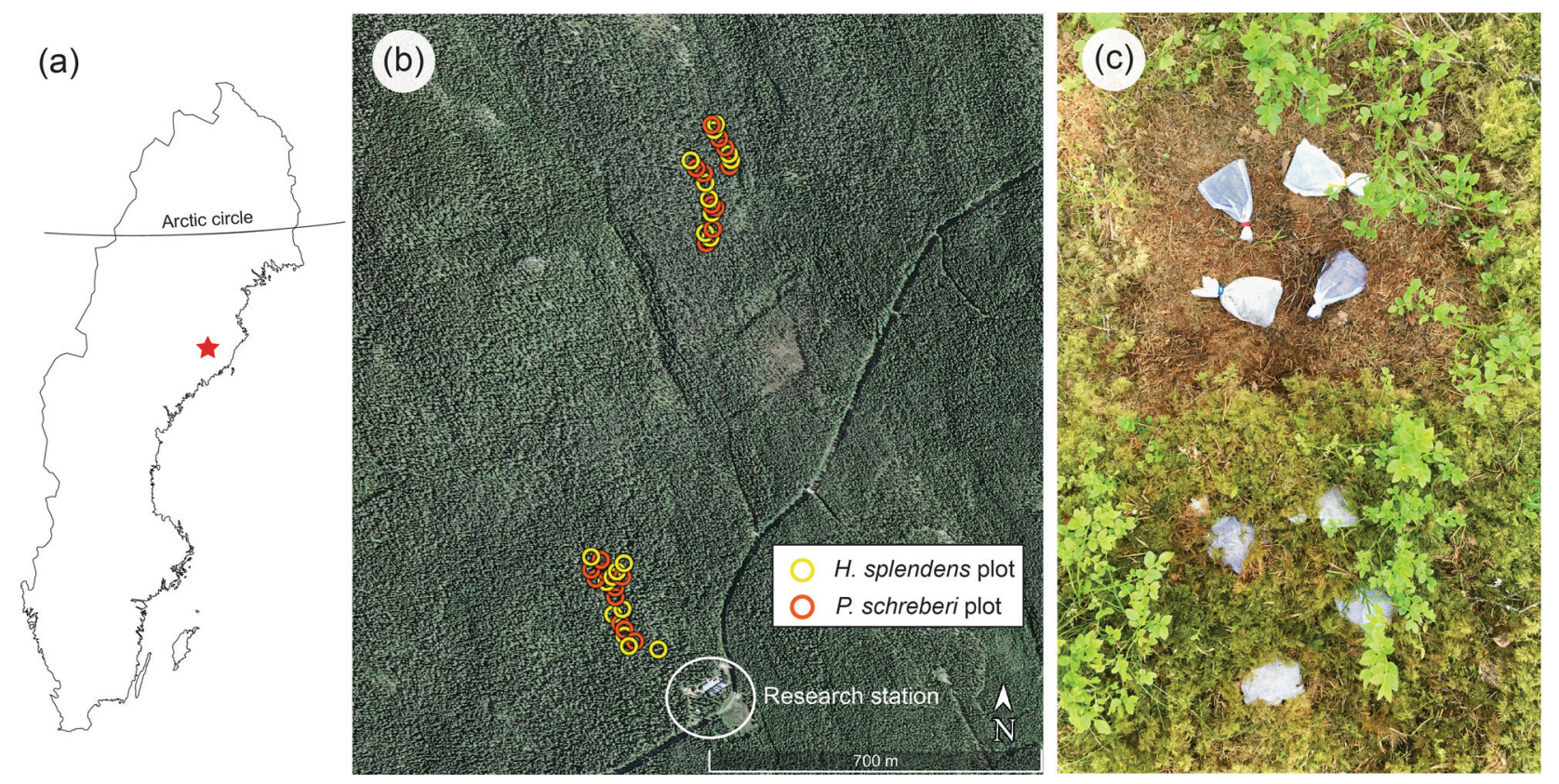

Figure 1. a Location of the study site in northern Sweden (map source: Vemaps.com). b Distribution of the plots in the two sites (image source: Google Earth Pro). c Example of a Hylocomium splendens plot. Each plot was divided in two subplots, one where the bryosphere had been removed and one where the bryosphere had not been removed. In each subplot, there were four litterbags, that is, a combination of two litter types (birch leaves or moss shoots), and two mesh sizes $(1.3 \times 1.1 \mathrm{~mm}$, or $1.0 \times 0.2 \mathrm{~mm})$.

each site) or by $H$. splendens ( 10 plots in each site). To minimise litter loss during transport, the litterbags were previously wetted using a spray bottle. At each plot, we placed four of the eight litterbags (that is, the factorial combination of two litter types and two mesh sizes) on a subplot where the bryosphere was not altered, and four of the eight litterbags on an adjacent $40 \times 40 \mathrm{~cm}$ subplot where the bryosphere had been removed (Figure 1c). The bryosphere was removed by hand, taking care to minimise disturbance to other plants and to the surface humus, on 22 May 2019. In bryospherecovered subplots, the litterbags were embedded in the centre of the bryosphere profile. To do this, we manually parted some moss shoots and placed the litterbags flat about $2-4 \mathrm{~cm}$ above the humus surface (Figure lc). Litter intercepted by the bryosphere is first decomposed in the upper and middle bryosphere before reaching the humus interface later in the decomposition process (Startsev and others 2008; De Long and others 2016). Thus, the placement of our litterbags in the centre of the bryosphere profile is intended to mimic conditions typical of the early stages of litter decomposition, in line with the relatively short-term nature of the study (De Long and others 2016). We used metal pins to ensure the litterbags remained embedded in the moss layer or made good contact with the soil.
At each plot, we installed two temperature loggers $(\mathrm{N}=80$; iButtons, Maxim Integrated) on 27 July 2019, that is, one in each bryosphere-covered subplot and one in each bryosphere-removed subplot. The loggers were placed underneath the finermesh moss litterbag and set to record the temperature every $4 \mathrm{~h}$ over the entire incubation period. For each logger, we calculated mean daily temperature and daily range for each of four observation periods: spring (March-May), summer (JuneAugust), autumn (September-November), and the snow-covered period between 19 November 2019 and 10 May 2020. We then calculated the change in mean daily temperature (and, separately, in daily range) due to bryosphere removal as the mean daily temperature (and daily range) in bryosphere-removed subplots minus mean daily temperature (and daily range) in bryosphere-covered subplots, for each observation period and for each plot.

\section{Litter Mass Loss and Micro-Arthropod Abundance}

We collected the litterbags from half of the plots (that is, $10 \mathrm{P}$. schreberi plots and $10 \mathrm{H}$. splendens plots from each site) between 26 September 2019 and 7 October 2019 (that is, about 4 months after the 
litterbags were deployed). Because our microarthropod extraction system could only fit 60 litterbags at a time, the 160 litterbags were collected in three sets of 48 to 56 litterbags (comprising whole plots of both moss species and from both sites). The litterbags were transported in air-tight plastic bags to SLU-Umeå, where they were immediately placed in Tullgren funnels for microarthropod extractions. The litterbags were carefully opened and placed upside down to facilitate microarthropod extraction. The extraction lasted for four days, and the extracted fauna was collected in $70 \%$ ethanol solution. The litter materials were then oven-dried at $60{ }^{\circ} \mathrm{C}$ for $24 \mathrm{~h}$ and weighed to calculate litter mass loss as a percentage of the initial mass of dry litter. The second half of the litterbags $(\mathrm{N}=160)$ was collected between 28 August 2020 and 7 September 2020 (that is, about 16 months after the litterbags were deployed), and we followed the same procedure to extract microarthropods and calculate litter mass loss. Damage to the litterbags in the field and sample mishandling meant that data of litter mass loss were available for 319 out of 320 litterbags, and data from microarthropod extractions were available for 302 litterbags.

We assessed the abundance of mites (Acari) and Collembola in each sample using a Wild Heerbrugg M400 dissecting microscope with 6-32 $\times$ magnification. Mites were assigned to one of four major taxonomic and trophic groups: Oribatida (fungivorous/omnivorous), Mesostigmata (predaceous), Prostigmata belonging to the family Tydeidae (fungivorous), and all other Prostigmata (predaceous), following Krantz and Walter (2009), and Walter and Proctor (2013). We did not find any Astigmata (fungivorous) in our samples. Because micro-arthropod activity (and, therefore, its effect on decomposition) depends on micro-arthropod biomass (Wood and Lawton 1973; Petersen and Luxton 1982), and given the high abundance of juvenile mites in our samples, we applied a correction factor to the abundance of juvenile mites to account for their smaller biomass relative to adults. Specifically, bigger juvenile mites (that is, those that could be confidently assigned to a morphologic group) were applied a correction factor of 0.238 based on published overall juvenile to adult mass ratios (Block 1966; Wood and Lawton 1973; Mercer and others 2001). Smaller (unidentified) juvenile mites were considered larvae and applied a correction factor of 0.077, after Wood and Lawton (1973) and Mercer and others (2001). All Collembola were considered fungivorous, as we did not find any individuals belonging to the predaceous family Frieseinae (Holtkamp 2008). In each sample, we added the number of mites and Collembola from all groups to calculate a measure of total micro-arthropod abundance. By collecting the litterbags in sets, and over a few days in each year, we sought to minimise the effect of time of harvest on abundance and composition of micro-arthropods and to ensure that the effects of the experimental treatments prevailed.

\section{Statistical Analysis}

We used R version 4.0.3 (R Core Team 2020) for all analyses and figures. Micro-arthropod community composition was analysed using the $\mathrm{R}$ package vegan (Oksanen and others 2020). Micro-arthropod community composition was analysed at the functional group level, which included the following groups: Oribatida mites, Mesostigmatida mites, Prostigmatida (Tydeidae) mites, other Prostigmatida mites, unidentified juvenile mites, and Collembola. We tested the effect of litter type, bryosphere removal, moss species and litterbag mesh size on composition using permutational multivariate analysis of variance (PERMANOVA; Anderson 2001), as implemented in the function 'adonis2', restricting permutations to within plots. PERMANOVA was carried out on a distance matrix computed using the 'Bray-Curtis' dissimilarity index (Faith and others 1987). We used non-metrical multidimensional scaling (NMDS; Clarke 1993) on the untransformed data to visualize the data. To test the association between micro-arthropod community composition and litter decomposition rates, we used the function 'envfit' to fit the variable litter mass loss onto the ordination and assess the statistical significance of the association through permutation tests (restricted to within plots).

Univariate data analysis was based on linear mixed effects models, as implemented in the $\mathrm{R}$ package nlme (Pinheiro and others 2020). Total micro-arthropod abundance was analysed by fitting an interaction between the factors 'bryosphere presence' (bryosphere present or removed) and 'litter type' (birch or moss) as fixed effects. The dominant species of the bryosphere (P. schreberi or $H$. splendens), mesh size of the litterbags, and time of incubation (4 or 16 months) were also included in the model as additive fixed effects and allowed to interact with the bryosphere presence and litter type interaction. Site was included as an additive fixed effect. To account for the nested structure of the experimental design (that is, litterbags were grouped in plots), plot was included as a random 
effect. Litter decomposition (estimated as \% mass loss) was analysed by fitting an interaction between the covariate 'micro-arthropod abundance' and the factors 'bryosphere presence' and 'litter type' as fixed effects. As in the previous model, the dominant species of the bryosphere, mesh size of the litterbags, and time of incubation were also included as additive fixed effects and allowed to interact with the previous variables, and site was included as an additive fixed effect. Plot was included as a random effect.

Change in mean daily temperature due to bryosphere removal was analysed by fitting an interaction between season and moss species as fixed effects. Site was added as an additive fixed effect, and plot as a random effect. In all models, we used a constant variance function ('varIdent') to account for variance heterogeneity among factor variables (Zuur and others 2009). Marginal $\mathrm{R}^{2}$ values, that is, the proportion of the total variance explained by the fixed effects, and conditional $\mathrm{R}^{2}$ values, that is, the variance explained by both fixed and random effects (Nakagawa and others 2017), were calculated using the package MuMIn (Barton 2020). Statistical significance of slopes for specific covariate and factor combinations was computed using the function 'emtrends' in the package emmeans (Lenth 2020).

\section{RESUlTS}

\section{Micro-Arthropod Abundance}

Most identified micro-arthropods extracted from the litterbags were Oribatid mites $(67 \%)$, followed by Mesostigmatid mites (14\%), Collembola (13\%), Prostigmatid mites belonging to the family Tydeidae $(4 \%)$ and other Prostigmatida (1\%) (Table S1). Micro-arthropod community composition responded most strongly to litter type $\left(\mathrm{R}^{2}=0.124\right)$ and bryosphere removal $\left(\mathrm{R}^{2}=0.067\right)$ (Table $\left.\mathrm{S} 2\right)$. Bryosphere presence and moss litter were associated with higher abundances of Oribatid mites and Collembola, while bryosphere removal and birch litter were associated with higher abundances of Mesostigmatid, Prostigmatid, and unidentified juvenile mites (Figure 2). Micro-arthropod composition was not significantly associated with litter mass loss $\left(\mathrm{R}^{2}=0.032, P=0.674\right)$.

Total micro-arthropod abundance was 29\% lower in litterbags placed on the soil in bryosphereremoved subplots than in litterbags embedded in the bryosphere layer (that is, in bryosphere-covered subplots) (Figure 3, Table S3). The negative effect of bryosphere removal on total micro-

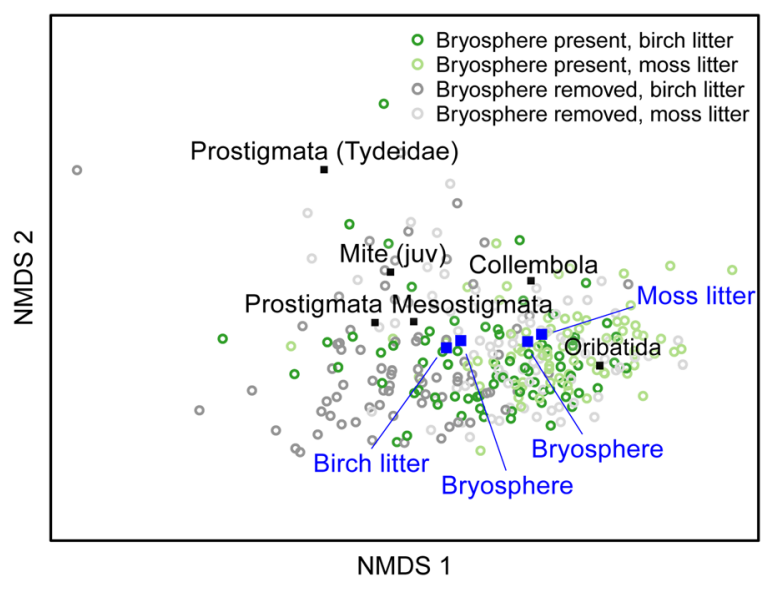

Figure 2. Non-metrical multidimensional scaling of micro-arthropod abundance. Micro-arthropods were grouped by the morphological and trophic groups Collembola, Oribatida, Mesostigmata, Prostigmata belonging to the family Tydeidae, other Prostigmata, and unidentified juvenile mites. Open circles represent individual samples. Blue symbols represent treatment centroids. The NMDS had a stress value of 0.14 .

arthropod abundance depended on the moss species that dominated the bryosphere (Figure 3, Table S3): effects were stronger for $H$. splendens bryospheres (where abundance decreased by $41 \%$ ) than for $P$. schreberi bryospheres (where abundance decreased by $14 \%$ ). Further, the decrease in abundance due to bryosphere removal was greater in litterbags collected after 16 months than after 4 months (Table S3). Litter type had the strongest main effect on micro-arthropod abundance: moss litterbags had $82 \%$ higher abundance than birch litterbags, but litter type did not mediate the effect of bryosphere removal on abundance. Finally, the mesh size of the litterbags had no significant effect on micro-arthropod abundance.

\section{Litter Mass Loss}

Removal of the bryosphere significantly reduced litter mass loss, by on average $28 \%$ (Figure 4 , Table S4). Moss species had a marginally non-significant effect on overall litter mass loss $(P=0.065)$, through being $12 \%$ higher in $H$. splendens plots than in $P$. schreberi plots. Litter type also affected litter mass loss, through being $42 \%$ higher for birch than moss litter. However, neither moss species nor litter type mediated the effect of bryosphere removal on litter mass loss (Table S4). Mesh size also had no significant effects on litter mass loss. The duration of the incubation mediated both the effect of bryosphere removal and of litter type on litter mass loss, because both effects were 


\section{4 months}

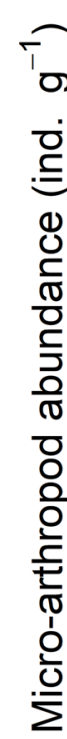

\section{0}

o

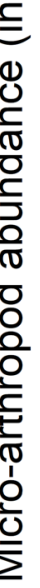

응 80

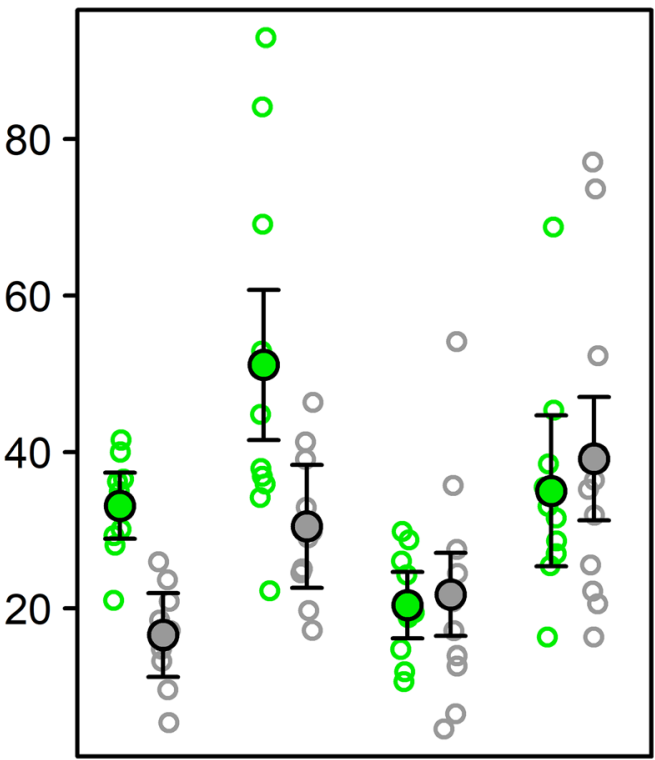

Litter:

Moss Birch Moss

\section{Bryosphere: $H$. splendens}

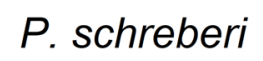

16 months

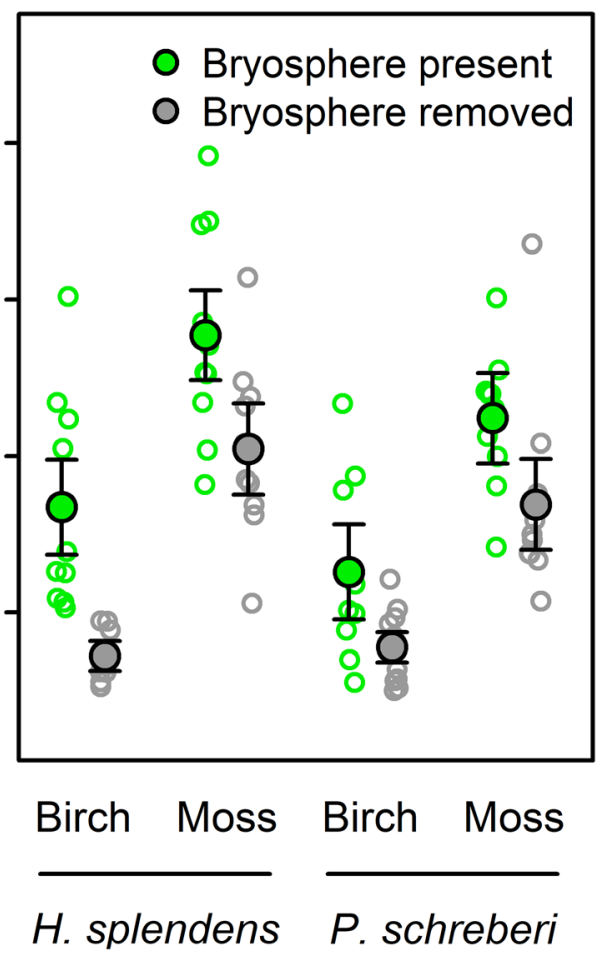

Figure 3. Micro-arthropod abundance on a dry litter weight basis in litterbags collected in (left) September 2019 (that is, after a 4-month field incubation) and (right) August 2020 (that is, after a 16-month field incubation) in bryospheres dominated by H. splendens or by P. schreberi, in birch or moss litter, and in bryosphere-removed or bryosphere-present subplots. Within the same subplot and litter type, the data of litterbags of both mesh sizes were aggregated because mesh size had no significant effect on total micro-arthropod abundance (Table S3). Open symbols indicate individual observations, solid symbols are means, and bars are $95 \%$ confidence intervals.

significantly greater after 16 months than after 4 months (Table S4). Overall, mass loss was $64 \%$ higher in litterbags that were collected after 16 months compared to litterbags collected after 4 months.

Micro-arthropod abundance was not correlated with litter mass loss overall (Table S4). However, litter type mediated the correlation between microarthropod abundance and litter mass loss, because micro-arthropod abundance was on average positively correlated with mass loss in birch litter $(P=0.001)$ but not in moss litter $(P=0.13)$ (Figure 5). Bryosphere removal and moss species did not alter the relationship between micro-arthropod abundance and litter mass loss (Table S4).

\section{Ground Temperature}

Mean temperature was significantly lower (by on average $0.32{ }^{\circ} \mathrm{C}$ ) on the ground in bryosphere-removed subplots compared to in the bryosphere of the bryosphere-covered subplots in summer and autumn, but was similar during the snow period and during the snow-free spring period (Figure 6, Table S5). Daily temperature range did not differ significantly between bryosphere-removed and bryosphere-covered subplots, although we did find some evidence of a lower temperature range in bryosphere-removed subplots during the summer (that is, by $-0.35{ }^{\circ} \mathrm{C} ; P=0.066$ ). Differences in mean daily temperature or daily temperature range between bryosphere-covered and bryosphere-removed subplots were similar in $H$. splendens and in P. schreberi bryospheres (Table S5).

\section{Discussion}

Litter decomposition at small spatial scales is mainly controlled by micro-climate (which is largely driven by habitat structure), litter quality, and the composition and activity of the decomposer biota (Prescott 2010; Makkonen and others 2012). Here, we used a litterbag experiment to investigate the effect of forest floor structure (that is, different 


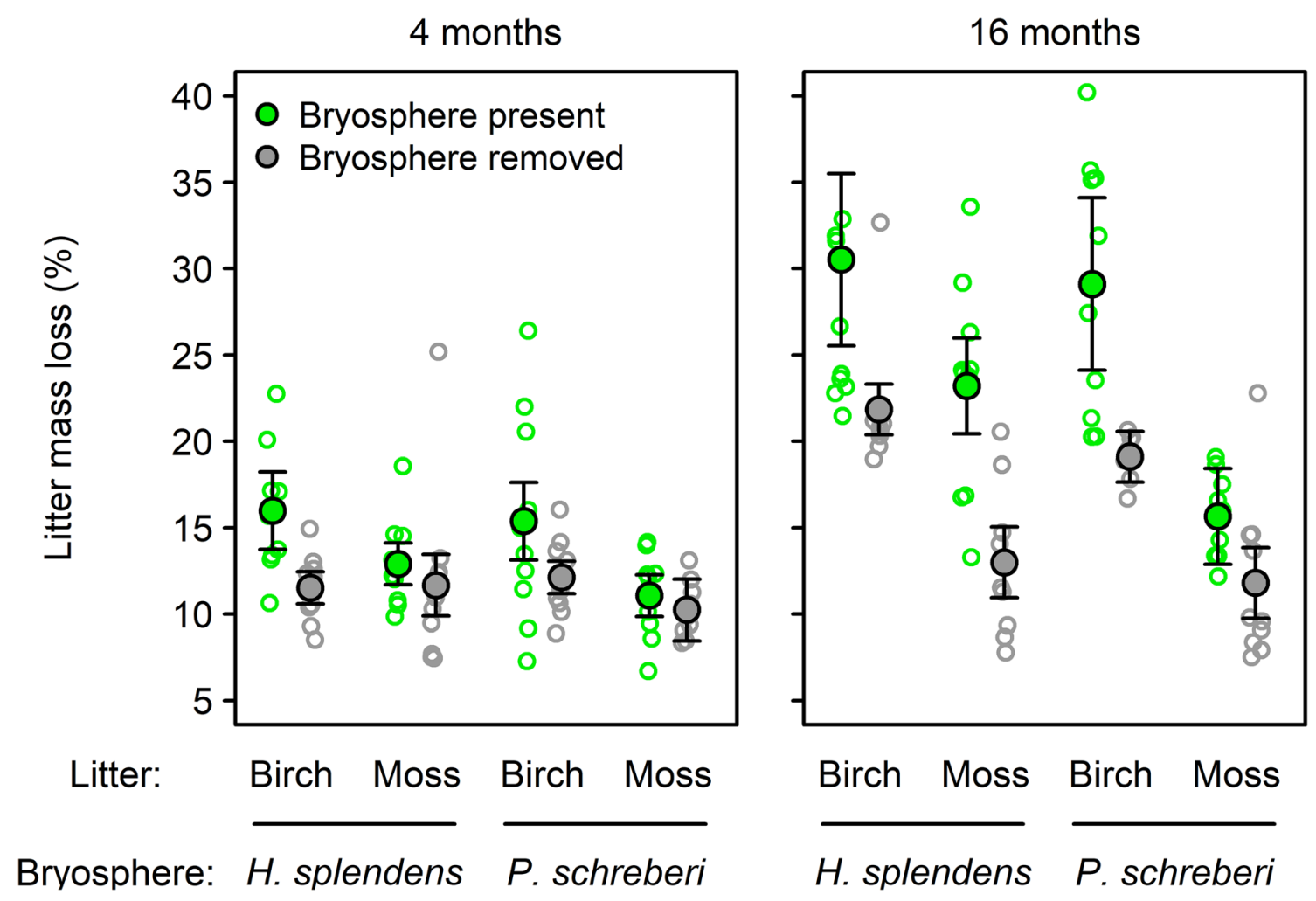

Figure 4. Litter mass loss in litterbags collected in (left) September 2019 (that is, after a 4-month field incubation) and (right) August 2020 (that is, after a 16-month field incubation) in bryospheres dominated by H. splendens or by P. schreberi, in birch or moss litter, and in bryosphere-removed or bryosphere-present subplots. Within the same subplot and litter type, data of litterbags of both mesh sizes were aggregated because mesh size had no effect on mass loss (Table S4). Open symbols indicate individual observations, solid symbols are means, and bars are $95 \%$ confidence intervals. One extreme observation (67\% mass loss from a birch litterbag in a H. splendens bryosphere-present plot collected in 2020) was not plotted to improve clarity.

bryosphere species, and bare ground), litter type, and micro-arthropod abundance on litter decomposition in boreal forests. We show that bryosphere loss substantially impairs litter decomposition, and that this bryosphere effect is generally not altered by moss species or litter type, or associated with micro-arthropod abundance or composition.

Both micro-arthropod abundance and decomposition rates were higher in litterbags embedded in the bryosphere compared to litterbags on bare ground, in line with our first hypothesis. This is also consistent with previous studies, which have attributed the positive effects of the bryosphere on micro-arthropod abundance and on litter decomposition rates to improved micro-climatic conditions (Jackson and others 2013, De Long and others 2016). We note that our litterbags were placed in the centre of the bryosphere profile, and that even stronger bryosphere effects are likely to occur in the lower parts of the bryosphere (De Long and others 2016). Increased temperature and moisture in the bryosphere may be important in promoting the decomposer subsystem (Lindo and Winchester 2007; Makkonen and others 2012). Although we did not measure moisture content, our finding of higher mean temperatures in summer and autumn in the bryosphere compared to bare ground indicates that improved micro-climate in the bryosphere could have enhanced soil biota activity and thus decomposition. Given the lower density of the bryosphere compared to soil, a lower thermal inertia in the bryosphere compared to on bare ground could explain the higher temperatures that we found in the bryosphere. Further, our finding that total micro-arthropod abundance was generally uncorrelated with litter decomposition is in line with previous studies frequently showing small or negligible effects of soil fauna on litter decomposition in boreal ecosystems (Wall and others 2008; Makkonen and others 2012; García-Palacios and others 2013; Barreto and Lindo 2018) and indicates that other biotic or abiotic changes in- 
4 months

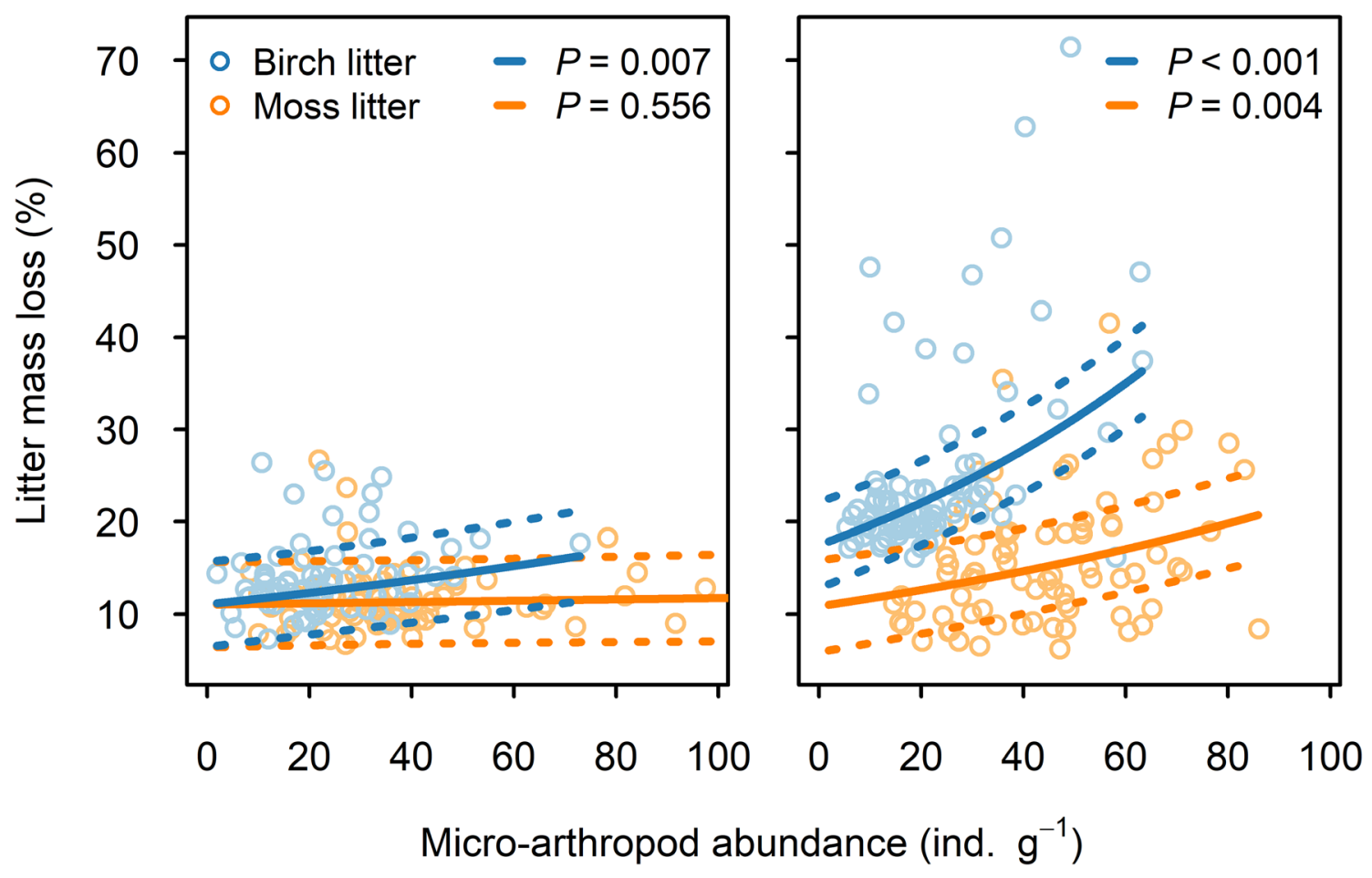

Figure 5. Litter mass loss against micro-arthropod abundance in litterbags collected in (left) September 2019 (that is, after a 4-month field incubation) and (right) August 2020 (that is, after a 16-month field incubation), in birch versus moss litterbags. The effect of micro-arthropod abundance on litter mass loss was not mediated by bryosphere removal, moss species, or litterbag mesh size, and data were therefore pooled across those variables (Table S4). Open circles are individual observations. Fitted slopes (solid lines) and their 95\% confidence intervals (dashed lines) and $P$ values are based on a linear mixed effects model including the logarithm of mass loss as a response variable, the interaction between micro-arthropod abundance, litter type and sampling year as fixed effects, and plot as a random effect. One extreme observation (a 2019 moss litter sample with an abundance of 149 ind. $\mathrm{g}^{-1}$ and a mass loss of $11.5 \%$ ) was not plotted to improve clarity.

duced by the bryosphere are the main drivers of the observed higher litter decomposition rates in the bryosphere.

Bryosphere removal also altered the composition of the micro-arthropod community. The presence versus absence of the bryosphere can potentially impact faunal composition and therefore their trophic interactions, which could in turn impact on microbial activity (Kardol and others 2016) and litter decomposition (Tan and others 2020). However, we found no evidence that changes in microarthropod community composition due to bryosphere removal influenced decomposition. This is despite our finding that litterbags in the bryosphere had greater abundance of Oribatid mites and Collembola, which can potentially facilitate microbial decomposition through breakdown of litter (Briones 2014). Further, litterbags on bare ground had greater abundance of predatory mites (e.g., Mesostigmatida), which could potentially impair the effects of prey species of Oribatid mites and Collembola (Hedlund and Öhrn 2000). Instead, we found that variation in micro-arthropod community composition in response to important environmental variables (that is, litter type, bryosphere presence, and bryophyte species) had no effect on litter decomposition rates.

We found no evidence that bryosphere effects on litter decomposition differed between $P$. schreberi and $H$. splendens bryospheres, which is inconsistent with our second hypothesis. Further, a greater decrease in micro-arthropod abundance occurred following removal of $H$. splendens than $P$. schreberi bryospheres, suggesting that $H$. splendens creates a more favourable habitat for micro-arthropods, also contrary to our second hypothesis. Thermal dynamics within the bryosphere did not differ between $P$. schreberi and H. splendens bryospheres, as indicated by their similar mean temperatures and daily temperature range. It is, however, possible 

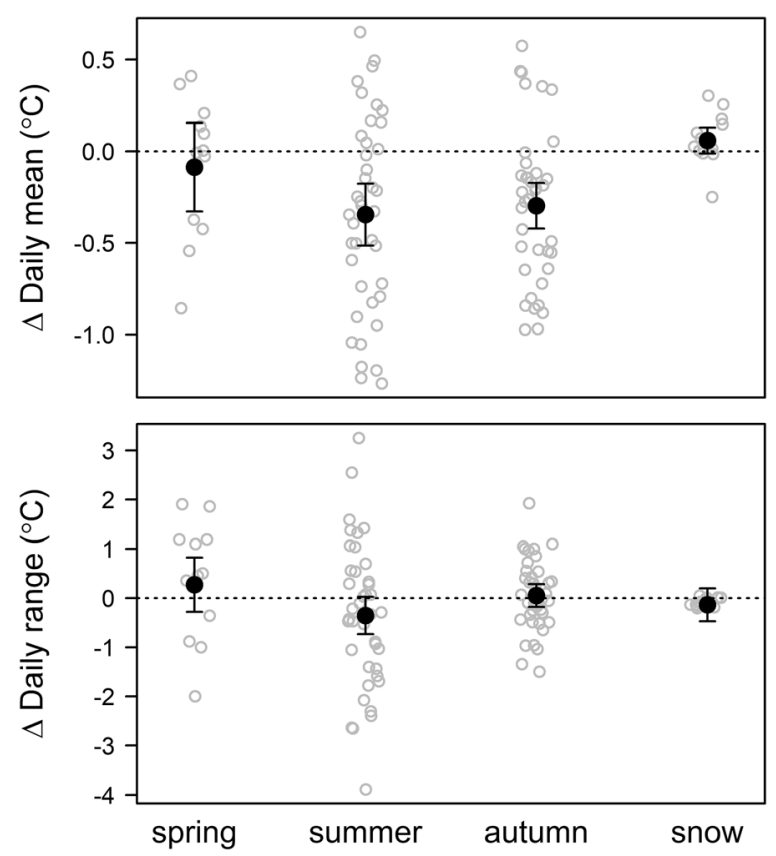

Figure 6. Change in (top) mean daily temperature and (bottom) daily range at the ground surface in bryosphere-removed subplots, relative to the bryosphere in adjacent bryosphere-covered subplots (that is, negative values indicate that bryosphereremoved subplots were [top] colder and [bottom] had lower temperature variation than bryosphere-covered subplots) for four observation periods: spring (MarchMay), summer (June-August), autumn (SeptemberNovember), and the snow-covered period between 19 November 2019 and 10 May 2020. Grey open symbols are observations averaged by observation period and plot. Black solid symbols are means and 95\% confidence intervals.

that although $P$. schreberi bryospheres have higher water holding capacity than $H$. splendens bryospheres (Elumeeva and others 2011), H. splendens may prefer wetter environments (Busby and Whitfield 1978), which could have promoted abundance of micro-arthropods in $H$. splendens bryospheres. Additionally, biological nitrogen fixation has been observed to be higher in H. splendens than in P. schreberi bryospheres in boreal forests (Lagerström and others 2007). Therefore, higher nitrogen availability could have contributed to the observed higher micro-arthropod abundance in litterbags on $H$. splendens bryospheres through supporting greater abundance of microbes and micro-fauna (that is, nematodes and tardigrades), which some micro-arthropods feed upon. This interpretation agrees with our observation (although marginally statistically non-significant) of increased decomposition in $H$. splendens compared to in $P$. schreberi, and with previous findings that the abundance of micro-fauna is higher in $H$. splendens than in P. schreberi bryospheres (Jonsson and others 2015). However, differences in bryosphere effects on micro-arthropod abundance between moss species were not reflected in litter decomposition rates, which supports the observation that micro-arthropod abundance had little overall effect on litter decomposition.

Bryosphere effects on litter decomposition were not mediated by litter type, contrary to our third hypothesis. Specifically, our results indicate that the observed higher micro-arthropod abundance in the bryosphere compared to bare soil did not enhance decomposition of lower-quality P. schreberi litter more than decomposition of higher-quality $B$. pendula litter, in contrast both to our hypothesis and to previous studies showing greater soil faunal effects on decomposition of lower-quality litter (Yang and Chen 2009; Milcu and Manning 2011; Joly and others 2020). However, we found that the association between overall micro-arthropod abundance (that is, across all litterbags) and litter decomposition rates was mediated by litter type, because higher abundance of micro-arthropods was associated with enhanced decomposition of higherquality $B$. pendula litter but not of lower-quality $P$. schreberi litter. Although our correlative analysis cannot rule out that changes in litter mass loss and micro-arthropod abundance were driven by covariation with unaccounted for variables, our results suggest that higher-quality litter may actually lead to stronger faunal effects on decomposition, contrary to our expectation, but in agreement with previous manipulative experiments (Schädler and Brandl 2005; Perez and others 2013; Fujii and others 2018; Tan and others 2020). One possible explanation is that the detritivorous activity of micro-arthropods is impaired in $P$. schreberi litter because of its lower quality, while in B. pendula litter, they could have a greater effect in enhancing litter decomposition through feeding on detritus and stimulating microbial communities.

Overall, we found that despite the higher microarthropod abundance (and, presumably, higher moisture availability; Wardle and others 2003) in $P$. schreberi litter, possibly as a consequence of its high pore space (Salmane and Brumelis 2008; Glime 2017), the higher-quality B. pendula litter decomposed faster, probably because it promoted microbial activity more because of its greater quality. Previous work on boreal ecosystems has identified higher C:N ratios and more recalcitrant compounds in moss litter compared to vascular plant litter as important drivers of the observed lower decomposition rates of moss litter (Wardle and others 2003; 
Del Giudice and Lindo 2017; Palozzi and Lindo 2017). Moreover, the effects of litter type and of bryosphere presence on litter decomposition were greater after 16 months than after 4 months, which point to long-lasting effects of litter type and bryosphere presence that intensify over time. In total, our results indicate that while forest floor structure (that is, bryosphere versus bare ground) and litter type did not interact, they were both strong drivers of micro-arthropod abundance and litter decomposition rates.

\section{Conclusions}

Our study shows that bryosphere loss in boreal forests impairs litter decomposition, and that this is unrelated to the concomitant decrease in microarthropod abundance, which point to other variables (for example, micro-climate, nutrient supply) driving bryosphere effects. Further, it demonstrates largely consistent effects of bryosphere loss (that is, across different moss species, litter types, and micro-arthropod abundances) on litter decomposition. This supports the view that the bryosphere buffers forest floor processes (Grau-Andrés and others 2021), possibly through regulation of thermal, moisture, or nutrient dynamics. Our results highlight the importance of the forest floor structure (that is, bryosphere versus bare ground) on controlling litter decomposition rates and suggest that loss of bryosphere cover, as is projected to occur in high-latitude ecosystems as a result of global change (Elmendorf and others 2012; Alatalo and others 2020), may impair litter decomposition. The reduced carbon and nutrient turnover that is associated with impaired litter decomposition could in the future impact on the capacity of boreal forest soils to supply nutrients for plant growth or to store carbon (Prescott 2010). Therefore, to improve our predictions of changes in litter decomposition and related ecosystem functions in moss-dominated ecosystems, future research should aim to better understand how global change will alter bryosphere cover.

\section{ACKNOWLEDGEMENTS}

This research was funded by a project grant (201700366) awarded by the Swedish Research Council Formas to Paul Kardol.

\section{FUNDING}

Open access funding provided by Swedish University of Agricultural Sciences.
Open Access This article is licensed under a Creative Commons Attribution 4.0 International License, which permits use, sharing, adaptation, distribution and reproduction in any medium or format, as long as you give appropriate credit to the original author(s) and the source, provide a link to the Creative Commons licence, and indicate if changes were made. The images or other third party material in this article are included in the article's Creative Commons licence, unless indicated otherwise in a credit line to the material. If material is not included in the article's Creative Commons licence and your intended use is not permitted by statutory regulation or exceeds the permitted use, you will need to obtain permission directly from the copyright holder. To view a copy of this licence, visit http://creativecommons.org/li censes/by/4.0/.

\section{DATA AVAILABILITY}

Data are available at https://doi.org/10.5061/dryad. 8cz8w9grp.

\section{REFERENCES}

Alatalo JM, Jägerbrand AK, Erfanian MB, Chen S, Sun S-Q, Molau U. 2020. Bryophyte cover and richness decline after 18 years of experimental warming in alpine Sweden. AoB PLANTS 12:plaa061.

Anderson MJ. 2001. A new method for non-parametric multivariate analysis of variance: NON-PARAMETRIC MANOVA FOR ECOLOGY. Austral Ecology 26:32-46.

Barreto C, Lindo Z. 2018. Drivers of decomposition and the detrital invertebrate community differ across a hummockhollow microtopology in Boreal peatlands. Écoscience 25:3948.

Barton K. 2020. MuMIn: Multi-Model Inference. https://CRAN. R-project.org $/$ package $=$ MuMIn

Block W. 1966. Seasonal Fluctuations and Distribution of Mite Populations in Moorland Soils, with a Note on Biomass. The Journal of Animal Ecology 35:487.

Bokhorst S, Wardle DA. 2013. Microclimate within litter bags of different mesh size: Implications for the 'arthropod effect' on litter decomposition. Soil Biology and Biochemistry 58:147152.

Bokhorst S, Wardle DA, Nilsson M-C, Gundale MJ. 2014. Impact of understory mosses and dwarf shrubs on soil micro-arthropods in a boreal forest chronosequence. Plant and Soil 379:121-133.

Briones MJI. 2014. Soil fauna and soil functions: a jigsaw puzzle. Frontiers in Environmental Science 2:7.

Busby JR, Whitfield DWA. 1978. Water potential, water content, and net assimilation of some boreal forest mosses. Canadian Journal of Botany 56:1551-1558.

Clarke KR. 1993. Non-parametric multivariate analyses of changes in community structure. Austral Ecol 18:117-143.

Coleman DC, Callaham M, Crossley Jr D. 2017. Secondary production: activities of heterotrophic organisms - the soil 
fauna. In: Fundamentals of soil ecology. 3rd ed. Academic press. pp 77-171. http://dx.doi.org/https://doi.org/10.1016/B 978-0-12-805251-8.00004-1

De Long JR, Dorrepaal E, Kardol P, Nilsson M-C, Teuber LM, Wardle DA. 2016. Understory plant functional groups and litter species identity are stronger drivers of litter decomposition than warming along a boreal forest post-fire successional gradient. Soil Biology and Biochemistry 98:159-170.

Del Giudice R, Lindo Z. 2017. Short-term leaching dynamics of three peatland plant species reveals how shifts in plant communities may affect decomposition processes. Geoderma 285:110-116.

Elmendorf SC, Henry GHR, Hollister RD, Björk RG, Bjorkman AD, Callaghan TV, Collier LS, Cooper EJ, Cornelissen JHC, Day TA, Fosaa AM, Gould WA, Grétarsdóttir J, Harte J, Hermanutz L, Hik DS, Hofgaard A, Jarrad F, Jónsdóttir IS, Keuper F, Klanderud K, Klein JA, Koh S, Kudo G, Lang SI, Loewen V, May JL, Mercado J, Michelsen A, Molau U, Myers-Smith IH, Oberbauer SF, Pieper S, Post E, Rixen C, Robinson CH, Schmidt NM, Shaver GR, Stenström A, Tolvanen A, Totland Ø, Troxler T, Wahren C-H, Webber PJ, Welker JM, Wookey PA. 2012. Global assessment of experimental climate warming on tundra vegetation: heterogeneity over space and time: Warming effects on tundra vegetation. Ecology Letters 15:164-175.

Elumeeva TG, Soudzilovskaia NA, During HJ, Cornelissen JHC. 2011. The importance of colony structure versus shoot morphology for the water balance of 22 subarctic bryophyte species: Factors affecting bryophyte water balance. Journal of Vegetation Science 22:152-164.

Faith DP, Minchin PR, Belbin L. 1987. Compositional dissimilarity as a robust measure of ecological distance. Vegetatio 69:57-68.

Fujii S, Cornelissen JHC, Berg MP, Mori AS. 2018. Tree leaf and root traits mediate soil faunal contribution to litter decomposition across an elevational gradient. Funct Ecol 32:840852.

García-Palacios P, Maestre FT, Kattge J, Wall DH. 2013. Climate and litter quality differently modulate the effects of soil fauna on litter decomposition across biomes. Ecol Lett 16:10451053.

Glime JM. 2017. Arthropods: Mites (Acari). Chapt. 9-1. In: Bryophyte Ecology. Volume 2. Bryological Interaction. Ebook sponsored by Michigan Technological University and the International Association of Bryologists. http://digitalcom mons.mtu.edu/bryophyte-ecology2/

Gornall JL, Jónsdóttir IS, Woodin SJ, Van der Wal R. 2007. Arctic mosses govern below-ground environment and ecosystem processes. Oecologia 153:931-941.

Grau-Andrés R, Wardle DA, Nilsson M-C, Kardol P. 2021. Precipitation regime controls bryosphere carbon cycling similarly across contrasting ecosystems. Oikos 130:512-524.

Hedlund K, Öhrn MS. 2000. Tritrophic interactions in a soil community enhance decomposition rates. Oikos 88:585-591.

Jackson BG, Martin P, Nilsson M-C, Wardle DA. 2011 . Response of feather moss associated $\mathrm{N}_{2}$ fixation and litter decomposition to variations in simulated rainfall intensity and frequency. Oikos 120:570-581.

Jackson BG, Nilsson M-C, Wardle DA. 2013. The effects of the moss layer on the decomposition of intercepted vascular plant litter across a post-fire boreal forest chronosequence. Plant and Soil 367:199-214.
Joly F-X, Coq S, Coulis M, David J-F, Hättenschwiler S, Mueller CW, Prater I, Subke J-A. 2020. Detritivore conversion of litter into faeces accelerates organic matter turnover. Commun Biol 3:660.

Jonsson M, Kardol P, Gundale MJ, Bansal S, Nilsson M-C, Metcalfe DB, Wardle DA. 2015. Direct and indirect drivers of moss community structure, function, and associated Microfauna across a successional gradient. Ecosystems 18:154-169.

Kardol P, Spitzer CM, Gundale MJ, Nilsson M-C, Wardle DA. 2016. Trophic cascades in the bryosphere: the impact of global change factors on top-down control of cyanobacterial $\mathrm{N}_{2}$-fixation. Ecology Letters 19:967-976.

Krantz GW, Walter DE. 2009. A manual of acarology. Lubbock, TX, USA: Texas Tech University Press.

Lagerström A, Nilsson M-C, Zackrisson O, Wardle DA. 2007. Ecosystem input of nitrogen through biological fixation in feather mosses during ecosystem retrogression. Functional Ecology 21:1027-1033.

Lenth R. 2020. emmeans: Estimated Marginal Means, aka LeastSquares Means. https://CRAN.R-project.org/package=emmea ns

Lindo Z, Gonzalez A. 2010. The bryosphere: an integral and influential component of the earth's biosphere. Ecosystems $13: 612-627$.

Lindo Z, Winchester NN. 2007. Oribatid mite communities and foliar litter decomposition in canopy suspended soils and forest floor habitats of western redcedar forests, Vancouver Island, Canada. Soil Biology and Biochemistry 39:2957-2966.

Lindo Z, Nilsson M-C, Gundale MJ. 2013. Bryophytecyanobacteria associations as regulators of the northern latitude carbon balance in response to global change. Global Change Biology 19:2022-2035.

Magilton M, Maraun M, Emmerson M, Caruso T. 2019. Oribatid mites reveal that competition for resources and trophic structure combine to regulate the assembly of diverse soil animal communities. Ecol Evol 9:8320-8330.

Makkonen M, Berg MP, Handa IT, Hättenschwiler S, van Ruijven J, van Bodegom PM, Aerts R. 2012. Highly consistent effects of plant litter identity and functional traits on decomposition across a latitudinal gradient. Ecol Lett 15:1033-1041.

Maraun M, Erdmann G, Fischer BM, Pollierer MM, Norton RA, Schneider K, Scheu S. 2011. Stable isotopes revisited: Their use and limits for oribatid mite trophic ecology. Soil Biology and Biochemistry 43:877-882.

Mercer RD, Gabriel AGA, Barendse J, Marshall DJ, Chown SL. 2001. Invertebrate body sizes from Marion Island. Antartic Science 13:135-143.

Milcu A, Manning P. 2011. All size classes of soil fauna and litter quality control the acceleration of litter decay in its home environment. Oikos 120:1366-1370.

Mitchell RJ, Urpeth HM, Britton AJ, Black H, Taylor AR. 2016. Relative importance of local- and large-scale drivers of alpine soil microarthropod communities. Oecologia 182:913-924.

Nakagawa S, Johnson PCD, Schielzeth H. 2017. The coefficient of determination R 2 and intra-class correlation coefficient from generalized linear mixed-effects models revisited and expanded. J R Soc Interface 14:20170213.

Nilsson M-C, Wardle DA. 2005. Understory vegetation as a forest ecosystem driver: evidence from the northern Swedish boreal forest. Frontiers in Ecology and the Environment 3:421-428.

Oksanen J, Blanchet FG, Friendly M, Kindt R, Legendre P, McGlinn D, Minchin PR, O'hara RB, Simpson GL, Solymos P. 
2020. vegan: Community Ecology Package. https://CRAN.Rproject.org $/$ package $=$ vegan

Palozzi JE, Lindo Z. 2017. Pure and mixed litters of Sphagnum and Carex exhibit a home-field advantage in Boreal peatlands. Soil Biology and Biochemistry 115:161-168.

Perez G, Aubert M, Decaëns T, Trap J, Chauvat M. 2013. Homefield advantage: A matter of interaction between litter biochemistry and decomposer biota. Soil Biology and Biochemistry 67:245-254.

Petersen H, Luxton M. 1982. A comparative analysis of soil fauna populations and their role in decomposition processes. Oikos 39:288

Pinheiro J, Bates D, DebRoy S, Sarkar D. 2020. nlme: Linear and Nonlinear Mixed Effects Models. https://CRAN.R-project.org/ package $=$ nlme

Prescott CE. 2010. Litter decomposition: what controls it and how can we alter it to sequester more carbon in forest soils? Biogeochemistry 101:133-149.

R Core Team. 2020. R: A language and environment for statistical computing. $\mathrm{r}$ foundation for statistical computing https:// www.R-project.org/

Salmane I, Brumelis G. 2008. The importance of the moss layer in sustaining biological diversity of Gamasina mites in coniferous forest soil. Pedobiologia 52:69-76.

Schädler M, Brandl R. 2005. Do invertebrate decomposers affect the disappearance rate of litter mixtures? Soil Biology and Biochemistry 37:329-337.

Startsev N, Lieffers VJ, Landhäusser SM. 2008. Effects of leaf litter on the growth of boreal feather mosses: Implication for forest floor development. Journal of Vegetation Science 19:253-260.

Street LE, Subke J-A, Sommerkorn M, Sloan V, Ducrotoy H, Phoenix GK, Williams M. 2013. The role of mosses in carbon uptake and partitioning in arctic vegetation. New Phytologist 199:163-175

Svartberget Research Station. 2020. Meteorological data from Svartberget, 1991-2019. SITES Data Portal. https://hdl.hand le.net/1 1676.1/FjfY8UI-3RhTAs6w-uo6f5UI. Last accessed 15/ 02/2021

Tan B, Yin R, Zhang J, Xu Z, Liu Y, He S, Zhang L, Li H, Wang L, Liu S, You C, Peng C. 2020. Temperature and moisture modulate the contribution of soil fauna to litter decomposition via different pathways. Ecosystems. https://doi.org/10.1007/ s10021-020-00573-w.
Turetsky MR, Mack MC, Hollingsworth TN, Harden JW. 2010. The role of mosses in ecosystem succession and function in Alaska's boreal forest. Canadian Journal of Forest Research 40:1237-1264

Vitt D, Finnegan L, House M. 2019. Terrestrial bryophyte and lichen responses to canopy opening in pine-moss-lichen forests. Forests 10:233.

Wall DH, Bradford MA, St. John MG, Trofymow JA, BehanPelletier V, Bignell DE, Dangerfield JM, Parton WJ, Rusek J, Voigt W, Wolters V, Gardel HZ, Ayuke FO, Bashford R, Beljakova OI, Bohlen PJ, Brauman A, Flemming S, Henschel JR, Johnson DL, Jones TH, Kovarova M, Kranabetter JM, Kutny L, Lin K-C, Maryati M, Masse D, Pokarzhevskii A, Rahman H, Sabar MG, Salamon J-A, Swift MJ, Varela A, Vasconcelos HL, White D, Zou X. 2008. Global decomposition experiment shows soil animal impacts on decomposition are climate-dependent. Global Change Biology 4:2661-2677.

Walter DE, Proctor HC. 2013. Mites in soil and litter systems. In: Walter DE, Proctor HC, editors. Mites: Ecology, Evolution \& Behaviour: Life at a Microscale. Dordrecht: Springer Netherlands. pp 161-228. https://doi.org/10.1007/978-94-007-71642_6

Wang S, Ruan H, Wang B. 2009. Effects of soil microarthropods on plant litter decomposition across an elevation gradient in the Wuyi Mountains. Soil Biology and Biochemistry 41:891897.

Wardle DA, Nilsson M-C, Zackrisson O, Gallet C. 2003. Determinants of litter mixing effects in a Swedish boreal forest. Soil Biology and Biochemistry 35:827-835.

Wood TG, Lawton JH. 1973. Experimental studies on the respiratory rates of mites (Acari) from beech-woodland leaf litter. Oecologia 12:169-191.

Yang X, Chen J. 2009. Plant litter quality influences the contribution of soil fauna to litter decomposition in humid tropical forests, southwestern China. Soil Biology and Biochemistry 41:910-918.

Zhou S, Butenschoen O, Barantal S, Handa IT, Makkonen M, Vos V, Aerts R, Berg MP, McKie B, Van Ruijven J, Hättenschwiler S, Scheu S. 2020. Decomposition of leaf litter mixtures across biomes: The role of litter identity, diversity and soil fauna. Pérez-Harguindeguy N, editor. J Ecol 108:22832297.

Zuur A, Ieno EN, Walker N, Saveliev AA, Smith GM. 2009. Mixed effects models and extensions in ecology with R. New York: Springer Science \& Business Media. 